\title{
Evaluating Shielding Effectiveness for Reducing Space Radiation Cancer Risks
}

\author{
Francis A. Cucinotta ${ }^{1 *}$, Myung-Hee Y. Kim² ${ }^{2}$ and Lei Ren ${ }^{3}$ \\ NASA Lyndon B. Johnson Space Center, Houston, Texas 77058 \\ Wyle Laboratories, Houston, Texas 77058
}

U.S.R.A., Division of Space Life Science Division, Houston, Texas 77058

* Corresponding author:

Dr. Francis A. Cucinotta, Chief Scientist

NASA Johnson Space Center

Houston TX, 77058

Francis.A.Cucinotta@nasa.gov

Phone: 281-483-0968

Fax: 291-483-3058 


\begin{abstract}
:
We discuss calculations of probability distribution functions (PDF) representing uncertainties in projecting fatal cancer risk from galactic cosmic rays (GCR) and solar particle events (SPE). The PDF's are used in significance tests of the effectiveness of potential radiation shielding approaches. Uncertainties in risk coefficients determined from epidemiology data, dose and dose-rate reduction factors, quality factors, and physics models of radiation environments are considered in models of cancer risk PDF's. Competing mortality risks and functional correlations in radiation quality factor uncertainties are treated in the calculations. We show that the cancer risk uncertainty, defined as the ratio of the 95\% confidence level (CL) to the point estimate is about 4-fold for lunar and Mars mission risk projections. For short-stay lunar missions ( $<180 \mathrm{~d})$, SPE's present the most significant risk, however one that is mitigated effectively by shielding, especially for carbon composites structures with high hydrogen content. In contrast, for long duration lunar (>180 d) or Mars missions, GCR risks may exceed radiation risk limits, with 95\% CL's exceeding $10 \%$ fatal risk for males and females on a Mars mission. For reducing GCR cancer risks, shielding materials are marginally effective because of the penetrating nature of GCR and secondary radiation produced in tissue by relativistic particles. At the present time, polyethylene or carbon composite shielding can not be shown to significantly reduce risk compared to aluminum shielding based on a significance test that accounts for radiobiology uncertainties in GCR risk projection.
\end{abstract}

Keywords: Space radiation, cancer risks, HZE ions, Lunar exploration, Mars exploration 


\section{Introduction}

Exposures to astronauts from galactic cosmic rays (GCR), made-up of high-energy protons and heavy ions, and solar particle events (SPE), comprised largely of low to medium energy protons, are important safety concerns for space exploration. Radiation risks include carcinogenesis, degenerative tissue effects such as cataracts (Cucinotta et al., 2001a) or heart diseases (Preston et al., 2003, Howe et al., 2004, Yang et al., 1982), and acute radiation syndromes (NCRP, 2000). Other risks such as damage to the central nervous system (CNS) are a potential concern for the GCR heavy ions (NAS, 1996). In the past, career radiation limits have been based on fatal cancer risks. For low Earth orbit (LEO) programs, an excess fatal risk of 3\% is used as criteria for dose limits, which are applied using age and gender specific dose to risk conversion factors. Radiation risk projection models serve several roles, which include setting dose-to-risk conversion factors needed to set dose limits, projecting mission risks, and evaluating the effectiveness of shielding or other countermeasures. For mission planning and operations, NASA uses the model recommended in the NCRP Report No. 132 for estimating cancer risks from space (NCRP, 2000). This model is similar to approaches described by other radiation risk assessment committees or in the scientific literature, employing a life-table formalism, epidemiological assessments of excess risk in exposed cohorts, such as the atomic-bomb survivors, and estimates of dose and dose-rate reduction factors (DDREF) and linear energy transfer (LET) dependent radiation quality factors.

Recently, NASA has recognized that projecting uncertainties in cancer risk estimates along with point estimates should be a requirement for ensuring mission safety, because point estimates alone have limited value when the uncertainties in the factors that enter into cancer risk calculations are large. Estimates of 95\% confidence intervals (CI) for various radiation protection scenarios are meaningful additions to the traditional point estimates, and can be used to explore the value of mitigation approaches, and of research that could narrow the various factors that enter into risk calculations. Uncertainties for low linear energy transfer (LET) radiation, such as gamma-rays, have been reviewed several times in recent years, and indicate that the major uncertainty is the extrapolation of cancer effects data from high to low doses and dose-rates 
(NCRP, 1997; BEIR, 1994). Other uncertainties include the transfer of risk across populations, and sources of error in epidemiology data including dosimetry, bias, and statistical limitations. For low LET radiation, probability distribution functions (PDF's) were described previously (NCRP, 1997). In estimating cancer risks for space radiation, additional uncertainties occur related to estimating the biological effectiveness of protons and heavy ions, and predicting LET spectra at tissue sites (Cucinotta et al., 2001b). The limited understanding of heavy ion radiobiology has been estimated to be the largest contributor to the uncertainty for space radiation effects (NAS, 1996), and radiation quality factors found to contribute the major portion of the uncertainties in a previous study (Cucinotta et al., 2001b).

In this paper we discuss modifications to our methodology for projecting cancer risk probability distributions for space missions, and apply the model to several space exploration mission scenarios including the evaluation of potential shielding approaches: First, in our previous work we had assumed the normal approximation for summing the additive contributions of many radiation components at tissue sites behind spacecraft shielding. The fluence weighted variance for each GCR charge and energy group was summed using the square root of the sum of the squares to estimate the standard deviation and confidence intervals. In the present work, we have used direct sampling over organ weighted LET distributions for the estimation of the 95\% CI's, and show that a log-normal distribution results from the analysis. A second modification is related to the uncertainties in the radiation quality factors. Previously, we had considered the range of experimental data for appropriate endpoints in order to develop a subjective PDF for the quality factor. In the present paper, we treat the quality factor, $Q(L)$, and its uncertainties as a functional relationship, which recognizes that values of Q(L) at different LET's are in-fact correlated by underlying biophysical processes. The final improvement made here is to accumulate Monte-Carlo trials directly from the double-detriment life-table rather than the cancer mortality rate. The life-table approach is used because in our previous estimates of cancer risk for the Mars mission (Cucinotta et al., 2001b), the upper level of the 95\% C.I. exceeded 10\% mortality risk, and for we expect that competing causes of death may significantly compress the higher values in the distribution.

Shielding is one approach that can be considered for mitigating radiation risks. Theoretical and computational efforts in the 1980's and 1990's have provided the basic understanding needed to design effective shielding approaches (Wilson et al., 1991, 1995, Cucinotta et al., 1998a). Materials of low atomic mass, especially hydrogen are expected to be 
optimal as radiation shields because they reduce the occurrence of secondary particles (neutrons, protons, and other recoils) and are more effective per unit mass of material in slowing down or stopping ions in atomic collisions, and fragmenting HZE ions. However, because relativistic ions in the GCR are not appreciably slowed down by appreciable amounts of any material, and are the largest inducer of secondary radiation produced in tissues, the role of shielding material selection for GCR is not clear. We show here that shielding materials can not be shown to have an important role in reducing GCR risks, because of their poor attenuation properties in any material combined with large risk model uncertainties. In contrast, exposures to SPE's are effectively mitigated by most shielding materials and there is a substantial reduction in mass that occurs when lower mass materials are selected for spacecraft structures.

\section{Life-Table Methodology}

We use the double detriment life-table to estimate radiation cancer mortality risks. In this approach the age-specific mortality of a population is followed over their entire lifespan with competing risks from radiation and all other causes of death described (Bunger et al., 1981). For a homogeneous population receiving an effective dose $E$, at age $a_{E}$, the probability of dying in the age-interval from $a$ to $a+1$ is described by the background mortality-rate for all causes of death, $M(a)$, and the radiation cancer mortality rate, $m\left(E, a_{E}, a\right)$, as

(1) $q\left(E, a_{E}, a\right)=\frac{M(a)+m\left(E, a_{E}, a\right)}{1+\frac{1}{2}\left[M(a)+m\left(E, a_{E}, a\right)\right]}$

The survival probability to live to age, $a$, following an exposure, $E$, at age, $a_{E}$, is

(2) $S\left(E, a_{E}, a\right)=\prod_{u=a_{E}}^{a-1}\left[1-q\left(E, a_{E}, u\right)\right]$

The excess lifetime risk (ELR) is the increased probability that an exposed individual will die from cancer and is defined by the difference in the conditional survival probabilities for the exposed and unexposed groups as 
(3) $\quad E L R=\sum_{a=a_{E}}^{\infty}\left[M(a)+m\left(E, a_{E}, a\right)\right] S\left(E, a_{E}, a\right)-\sum_{a=a_{E}}^{\infty} M(a) S\left(0, a_{E}, a\right)$

We use a finite cut-off of 101-years for the upper limit in Eq.(3) and expressions below. A minimum latency-time of 10-years is often used for low LET radiation (NCRP, 2000), however we will consider alternative assumptions for high-LET radiation. The risk of exposure induced death (REID) is the lifetime risk that an individual in the population will die from a cancer caused by his or her radiation exposure, defined by

(4) $R E I D=\sum_{a=a_{E}}^{\infty} m\left(E, a_{E}, a\right) S\left(E, a_{E}, a\right)$

In general, the value of the REID exceeds that of the ELR by about 10-20\%. Vaeth and Pierce (1990) have discussed special cases where the ELR is ill-defined and suggested that the REID is the preferred quantity for radiation protection. Radiation risk calculations are based on population data, however are used to estimate risks for individuals. Population data reflect gender differences, however also change with calendar year and often used for projections far into the future. For the astronaut population, the appropriateness of using the US average population can be questioned, because the so-called "healthy worker" effect is expected for astronauts.

For projecting lifetime cancer fatality risks, an age- and gender-dependent mortality rate per unit dose, estimated for acute gamma-ray exposures, is multiplied by the radiation quality factor and reduced by the dose- and dose-rate reduction factor (DDREF) (NCRP, 2000).

Additivity of effects of each component in a radiation field is assumed. Radiation mortality rates are largely modeled using the Japanese atomic-bomb survivor data. For transferring risks from the Japanese to US population two models are often considered. A multiplicative transfer model assumes radiation risks are proportional to spontaneous or background cancer risks. The additive transfer model assumes radiation acts independently of other cancer risks. However, the NCRP recommends (NCRP, 2000) a mixture model with fractional contributions from the multiplicative risk model or additive risk model. The radiation mortality rate is:

(5) $m\left(E, a_{E}, a\right)=\left[v E R R\left(a_{E}, a\right) M_{c}(a)+(1-v) \operatorname{EAR}\left(a_{E}, a\right)\right] \frac{\sum_{L} Q(L) F(L) L}{D D R E F}$ 
where $E R R$ and $E A R$ are the excess relative risk and excess additive risk per Sievert, respectively, $M_{c}(a)$ is the gender and age-specific cancer mortality rate in the US population, $F$ is the tissueweighted fluence and $L$ is the LET. In Eq.(5), $v$ is the fractional division between the assumption of the multiplicative and additive risk transfer models. For solid-cancer, it is assumed that $v=1 / 2$ and for leukemia that $v=0$.

\section{Uncertainties in the Projection Model}

Equation (5) consists of a product of several factors: the $E R R$ or $E A R$, the background cancer rates, $M c$, the effective dose represented by the physical dose, $F L$, times the radiation quality factor, $Q(L)$, and the dose- and dose-rate reduction factor, $D D R E F$. The limiting behavior of the addition of many random variables is well known as the normal distribution. In contrast, the limiting behavior of the multiplication of many random factors will be a log-normal distribution. We next consider estimates of the range of values and associated PDF's for each of these factors. Because the risk for longer duration missions exceeds a few percent, upper 95\% CIs may exceed $10 \%$. In such cases, the sampling of rates is insufficient and the expression for the REID given by Eq. (4) must be used because of competing risks from other causes of death that will reduce the likelihood of very large radiation risks. Therefore in the sampling approaches described below trials are accumulated for the REID rather than the mortality rate. A criteria used in our approach for formulating PDF's for various factors is ensure the PDF's are peaked at the values recommended by the NCRP (NCRP, 2000), such as the DDREF and Q, or in the current physics models of radiation environments and transport used in mission projections or spacecraft designs. As described below the model of Eq. (5) assumes that the dependence of risk with time after exposure and latency effects is independent of radiation quality, despite experimental evidence to the contrary. We ignore these uncertainties; however we replace the 10-year minima latency assumption made for solid cancer risk from low LET irradiation, by the step-in latency model (Pierce et al., 1996) used for the leukemia risk. We next describe the PDF's that represent the uncertainties in the projection model.

For sampling purposes, the low-LET mortality-rate per Sievert, $m_{L}$ is written 
(6) $m_{l}\left(E, a_{x}, a\right)=\frac{m_{0}\left(E, a_{x}, a\right)}{D D R E F} \frac{x_{D} x_{s} x_{T} X_{B}}{x_{D r}}$

where $m_{0}$ is the baseline mortality rate per Sievert (see Eq. (5)) and the $x_{\alpha}$ are quantiles (random variables) whose values are sampled from an associated probability distribution functions (PDF), $P\left(x_{\alpha}\right)$. Note that the DDREF applies only to the solid cancer risk and not the leukemia risk under the stated assumptions. The NCRP Report 126 (NCRP, 1997) defines the following subjective

PDF's, $P\left(x_{\alpha}\right)$, for each factor that contributes to the low LET-risk projection:

1. $P_{\text {dosimetry }}$ represents the random and systematic errors in the estimation of the doses received by atomic-bomb blast survivors. It is assumed as a normally-distributed PDF for bias correction of random and systematic errors in the dosimetry (DS86) with mean 0.84 and standard deviation 0.11 ;

2. $P_{\text {statistical }}$ represents the distribution in uncertainty in the risk coefficient $r_{0}$. It is assumed as a normally distributed PDF with a mean of one and a standard deviation of 0.15 ;

3. $P_{\text {bias }}$ represents any bias resulting for over- or under-reporting cancer deaths. $P_{\text {bias }}$ is assumed as a normal distribution with a most probable values of 1.1 and a $90 \%$ C.I. from 1.02 to 1.18 corresponding to a standard deviation of 0.05 ;

4. $P_{\text {transfer }}$ represents the uncertainty in the transfer of cancer risk following radiation exposure from the Japanese population to the US population. Both additive and relative risks models were considered by NCRP 126 in assessing the uncertainties in such transfer. $P_{\text {transfer }}$ is lognormal with mean 1 and standard deviation $0.26(\mathrm{GSD}=1.3)$;

5. $\quad P_{D r}$ represents the uncertainty in the knowledge of the extrapolation of risks to low dose and dose-rates, embodied in the dose and dose-rate reduction factor (DDREF). The NCRP assumed $P_{D r}$ to be a truncated triangle distribution starting at 1 and ending at 5 with a peak at 2 with a relative value of $1 / 4$ or $1 / 2$ at 1 or 5 , respectively, compared to the peak values for the DDREF at 2. This PDF is used to scale the low LET risk coefficient (mortality rates) in our estimates for space radiation.

The NCRP also considered a PDF for bias correction in projection of cancer risks over a lifetime. It is ignored herein because the astronaut population is generally over age 30 and the Japanese data is now complete for these ages. We also ignore the assumed "unknown uncertainties” from the NCRP 126 report (NCRP, 1997).

\section{Uncertainties Due to Radiation Quality Effects}

Radiation quality factors represent the largest uncertainty in estimating space radiation cancer risks. Past reviews on the relative biological effectiveness of high-LET radiation include the ICRU Report 40 (1986), NCRP Report 104 (1990), and more recently ICRP Report 92 (2003). The practice of assigning radiation quality factors followed by committees is to consider an average of the relative biological effectiveness (RBE) factors at low doses $\left(R B E_{\max }\right)$ for the most relevant experimental endpoints. Uncertainties in assignment of RBE's for protons and 
heavy ions arise for several reasons including sparseness of data for tumorigenesis in animal models or surrogate tissue or cellular endpoints, variability in reference radiation and doses and dose-rates employed, and lack of data over the LET range of interest. Also, linearity at low dose or dose-rates for the reference radiation or ions is often not sufficiently established in experiments. Statistical limitations often hinder studies at the low dose-rates of interest for space radiation protection. For high-LET radiation, a turn-over or bending found in the dose response for tumor induction and neoplastic transformation is observed at moderate doses, presenting further uncertainties in estimating the effectiveness of high-LET radiation at low dose-rates.

Figure 1 shows representative examples of the ratio of $R B E_{\max }$ to $Q$ for mouse tumors, cell transformation or mutations, or cytogenetic endpoints. The ratio is often 2- to 3-fold times higher or lower than unity, which indicates the expected deviation from $Q$ in available data.

Table 1 shows LET values at the maximum RBE found in past studies, selected from experiments with more than 5 ions studied. Large deviations from the Q peak at $100 \mathrm{keV} / \mu \mathrm{m}$ are observed in these experiments with a range from about 50 to $190 \mathrm{keV} / \mu \mathrm{m}$ for the peak. The number of past studies and endpoints used are limited if viewed as surrogate endpoints for human carcinogenesis. Track structure models suggest that each ion species would have distinct RBE curves of similar shape, however with curves for lower charge ions peaking at a lower LET than higher charged ions (Katz et al., 1971; Cucinotta et al., 1996; Nikjoo et al., 1999). Furthermore, above about 1-MeV/u, lower charged ions have a higher biological effectiveness than higher charged ions of identical LET. Based on track structure models, we expect that data sets that consider only a few ions are insufficient for defining the radiation quality dependence of $Q$. LET response curves also are predicted to depend on the target size (for e.g. gene or chromosome region), and intrinsic radiation sensitivity, which includes the competition with cell death. These factors likely vary between tissues.

To account for the uncertainties in quality factors, we introduce a trial function that has a shape guided both by experimental data and biophysical models, and sample from distributions of parameters that enter into the functional form. The $Q(L)$ trial function is defined

(7) $Q_{\text {trial }}(L)=\left\{\begin{array}{cc}1 & L<L_{0} \\ A L-B & L_{0} \leq L<L_{m} \\ C / L^{p} & L \geq L_{m}\end{array}\right.$ 
We sample values of $L_{0}, L_{m}$, p, and the maximum value, $Q_{m}\left(L_{m}\right)$ from PDF's described below. Using Eq.(7) we can then solve for values of the constants A, B, and C. Often discussed issues on the definition of $\mathrm{Q}(\mathrm{L})$ as embodied in Eq.(7) are the value of slope $p$ that controls the decrease in $Q(L)$ above a maximum, the maximum value of $Q(L)$, the LET where the maximum occurs, $L_{m}$, and the minimum LET where $Q(L)$ rises above unity, $L_{0}$. We note the ICRP-60 Q-function corresponds to $\mathrm{L}_{0}=10 \mathrm{keV} / \mu \mathrm{m}, \mathrm{L}_{\mathrm{m}}=100 \mathrm{keV} / \mu \mathrm{m}, \mathrm{p}=1 / 2$, and $\mathrm{Q}_{\mathrm{m}}=30$ such that $A=0.32, B=2.2, C=$ 300, and the ICRP-26 Q-function, $\mathrm{L}_{0}=3.5 \mathrm{keV} / \mu \mathrm{m}, \mathrm{L}_{\mathrm{m}}=172.5 \mathrm{keV} / \mu \mathrm{m}, \mathrm{p}=0$, and $\mathrm{Q}_{\mathrm{m}}=20$.

The parameter samplings are based on the following assumptions for PDF's:

a) $L_{0}$ : equal probability between 5 and $10 \mathrm{keV} / \mu \mathrm{m}$, and decreasing to zero at $1 \mathrm{keV} / \mu \mathrm{m}$, or above $15 \mathrm{keV} / \mu \mathrm{m}$.

b) $L_{m}$ : equal probability for LET values between 75 and $150 \mathrm{keV} / \mu \mathrm{m}$, and decreases to zero at $50 \mathrm{keV} / \mu \mathrm{m}$ or above $250 \mathrm{keV} / \mu \mathrm{m}$.

c) $p$ : equal probability between $\mathrm{p}=1 / 2$ and 1 , and decreasing to zero at $\mathrm{p}<0$ or $\mathrm{p}>2$.

d) $\mathrm{Q}_{\mathrm{m}}$ : log-normal distribution with mean value of 30 and GSD of 1.8.

Figure 2a shows examples of trial $Q(L)$ functions that contribute in the sampling procedures, and Figure $2 \mathbf{b}$ shows the resulting average $Q(L)$ and 95\% CI after 20,000 trials. The resulting range is smaller than in our previous report (Cucinotta et al., 2001b), however should be a reasonable estimate when the effects of dose protraction are not included in the uncertainty analysis.

\section{Uncertainties in Physics: Environments and Transport Codes}

Space dosimetry and radiation transport codes have been studied extensively in the past, and although there are no major scientific questions that lead to errors in the assessment of space radiation environments, there are practical limitations in space dosimetry and accelerator bench mark tests, or because the level of detail used in application of transport codes when compared to flight or accelerator data is incomplete. Common simplifications in flight comparisons to transport models are the use of an aluminum equivalent shielding approximation, simplified geometries, no description of orientation effects, and neglect of detector response functions (Nikjoo et al., 2002) for different radiation components. Statistical errors in the assessment of physical doses are quite small $(<5 \%)$, however inter-comparisons between laboratories have shown differences on the order of $10 \%$ for absorbed dose (Badhwar, 1997). Commonly used detectors are tissue equivalent proportional counters (TEPC’s), silicon detectors, and CR-39 plastic track detectors (Benton et al., 2002). Good agreement has been found in comparisons that have been made (see for e.g., Shinn et al., 1998; Badhwar and Cucinotta, 2000; Cucinotta et al., 
2000; Kim et al., 2003), especially when detector response functions are represented in the comparisons, however the number and nature of the comparisons is limited.

The PDF's for the uncertainties in LET spectra, should ensure the resulting dose equivalent is consistent with transport code comparisons to past spaceflight measurements for GCR. Based largely on comparisons of the HZETRN model to flight dosimetry results note above, a standard error of about 15\% for projection of the GCR dose equivalent is expected. However, a higher uncertainty for specific values of $F(L)$ are needed to account for the larger differences at higher LET flux values. We performed Monte-Carlo simulations which show that modest dose or dose equivalent differences between codes and data, do not prevent large deviations in flux versus LET comparisons to occur. A quantile, $x_{L}$, associated with a normal distribution, $P_{F}\left(x_{F}=F / F_{0}\right)$, where $F_{0}$ is the baseline $F(L)$ model, is used with a standard error that increases with LET to represent the higher uncertainties expected for prediction of neutron effects, and the difficulty in precisely defining stopping ions in complex geometries. The PDF is given a median of $x_{0 F}=0.65$ to ensure the resulting dose equivalent is in agreement with values from prior comparison between transport codes and flight measurements cited above. Standard deviations for different LET regions are given in Table 2. Results for the distribution of dose equivalents after sampling over LET spectra for a 600 day mission in deep space are shown in Figure 3, and indicate the expected error in the dose equivalent based on comparisons of transport codes to flight measurements in the past.

\section{PDF's for Space Exploration Missions}

The cancer risk projection for space missions are found by folding predictions of the tissue-weighted LET spectra behind space craft shielding, $d F / d L$, with the radiation cancer mortality rate to form a rate for a trial $J$ :

$$
m_{J}\left(E, a_{E}, a\right)=m_{I J}\left(E, a_{E}, a\right) \int d L \frac{d F}{d L} L Q_{\text {riat } J}(L) x_{L-J}
$$

(not shown are quantiles associated with low-LET mortality rate). Alternatively, particle specific energy spectra, $F_{j}(E)$ for each ion, $j$, can be used:

(9) $m_{J}\left(E, a_{E}, a\right)=m_{I J}\left(E, a_{E}, a\right) \sum_{j} \int d E F_{j}(E) L(E) Q_{\text {riat } J}(L(E)) x_{L-J}$ 
The result of equation (8) or (9) is then inserted into the expression for the REID of equation (4). In implementing a numerical procedure, we group the PDF's related to the risk coefficient of the normal form, which consist of the dosimetry, bias, and statistical uncertainties into a combined PDF, $P_{c m b}(\mathrm{x})$. After accumulating sufficient trials $\left(\sim 10^{5}\right)$, the results for the REID estimates are binned and the median values and confidence intervals found.

We use the $\chi^{2}$ test for determining if PDF's for two distinct shielding configurations or materials are significantly different. We denote the calculated PDF's for a REID of $R_{i}$ for two configurations or materials as $p_{1}\left(R_{i}\right)$ and $p_{2}\left(R_{i}\right)$, respectively. Each $p\left(R_{i}\right)$ follows a Poisson distribution with variance, $\sqrt{p\left(R_{i}\right)}$. The chi-squared, $\chi^{2}$ test for characterizing the dispersion between the two distributions is then,

$$
\chi^{2}=\sum_{n} \frac{\left[p_{1}\left(R_{n}\right)-p_{2}\left(R_{n}\right)\right]^{2}}{\sqrt{p_{1}^{2}\left(R_{n}\right)+p_{2}^{2}\left(R_{n}\right)}}
$$

Once $\chi^{2}$ is determined, the probability $P\left(n, \chi^{2}\right)$ that the two distributions are the same is calculated. If $\chi^{2}$ is sufficiently large such that $P\left(n, \chi^{2}\right)$ is less than about $20 \%$, is an indication that we can conclude that the two distributions lead to distinct cancer risks from GCR and/or SPE's, with the material with the lowest mean and upper 95\% CL values preferred for radiation protection. However, the opposite result indicates that the either the materials are approximately the same, or that the uncertainties in risk models prevents us from concluding that either configuration or material is superior for radiation protection properties. We evaluate $\chi^{2}$ for the LET dependent parts of the uncertainties (quality factors and physics) separately, since only these contributions explicitly depend on the modification of radiation fields by shielding.

\section{Results}

In the results described next we use values of $E R R$ and $E A R$ for solid cancers from the Japanese Longitudinal Lifespan Study Report No. 13 (Preston et al., 2003). Note that these values for females were found to about 15\% lower than the prior Report No. 12 (Pierce et al., 1996) used by NCRP Report No. 132 (NCRP, 2000) and values for males nearly the same in Reports 12 and 13. Values for $E R R$ and $E A R$ for leukemia were not updated in the latest report and we use the 
values from Pierce et al. (1996). We use life-tables (CDC, 2000) and background cancer mortality rates (SEER, 2000) for the average US population for the year 2000. For models we use the GCR free space environment of Badhwar et al. (1994b), the HZETRN transport code (Wilson et al., 1991, 1995), and the QMSFRG model of nuclear fragmentation cross-sections (Cucinotta et al., 2003). The CAMERA model (Billings and Yucker, 1973) is used for organ shielding with tissue weighting coefficients (NCRP, 2000). Figure 4 shows calculations of the point dose equivalent and the effective dose (tissue averaged organ dose equivalent) for various shielding materials calculated by the HZETRN/BRYNTRN codes for the solar minimum GCR environment and the August of 1972 SPE. Calculations predict that the effects of SPE are readily mitigated by shielding, the effects of GCR are not, and tissue shielding reduces the differences expected when comparing materials. For hydrogen shielding, the GCR effective dose is larger than the point dose because target fragments in tissue contribute about $50 \%$ of the effective dose, even though very little secondary radiation is produced directly in the hydrogen shield. Clearly, calculations or measurements of point dose equivalents mis-represent the effectiveness of shielding because of the role of secondary radiation produced in tissue. For calculations, we use 5,10 , and $20 \mathrm{~g} / \mathrm{cm}^{2}$ as representative of minimal or average shields.

Figure 5 shows calculations for the point estimate and 95\% CI's for risk versus LET for males exposed at age $40 \mathrm{y}$. The top panel shows risks at an absorbed dose of $0.01 \mathrm{~Gy}$ and the bottom panel at $0.1 \mathrm{~Gy}$. The solid squares are the resulting "fold-uncertainty" defined as the ratio of the 95\% CL to the point estimate. At high LET, a 5-fold uncertainty occurs at low absorbed dose, however at higher absorbed dose and near the peak LET effectiveness, the uncertainties are reduced to about 3 -fold due to competing causes of death limiting the upper levels of risk from radiation.

The variation of GCR and SPE over the solar cycle would be difficult to use as a trade variable in long-term planning and we therefore discuss calculations at solar minimum and near solar maximum. For solar maximum calculations, we assume the large solar particle event (SPE) of August, 1972 to occur during the inter-planetary part of the mission, and use a solar modulation parameter (Badhwar et al., 1994) of $1100 \mathrm{MV}$, typical of about two years past solar maximum, however when large SPE's often occur. We use a $16 \mathrm{~g} / \mathrm{cm}^{2}$ vertical height for the Mars $\mathrm{CO}_{2}$ atmosphere in our calculations. Table 3 shows fatal cancer risk projections at solar minimum for males and females of age 40 at the time of the mission. Cancer morbidity risks are about 50\% higher than mortality risks described here. Calculations are made for minimally 
shielded spacecraft of $5 \mathrm{~g} / \mathrm{cm}^{2}$ aluminum, and a heavily shielded one of $20 \mathrm{~g} / \mathrm{cm}^{2}$. Similar calculations near solar maximum are shown in Table 4 with an SPE fluence equivalent to the August of 1972 SPE is assumed to have occurred. At solar minimum, it is seen that a four-fold addition of mass reduces the cancer risk by only about $15 \%$. Results are different at solar maximum. Here a four-fold increase in shielding mass leads to more than two-fold reduction in cancer risk; solar protons are less penetrating than GCR and effectively mitigated by shielding. However for heavy shielding ( $\geq 20 \mathrm{~g} / \mathrm{cm}^{2}$ ), GCR dominates over SPE's and further addition of shielding provides marginal reductions. Each SPE is unique and has distinct fluence and energy spectra, and dose rates, therefore the shielding thickness where GCR doses exceed SPE doses vary from event to event.

An alternative to a shielding approach that adds mass is to optimize materials used in spacecraft structures or planetary habitats to reduce radiation risk. Figure 6 shows PDF's for the GCR as solar minimum for aluminum, polyethylene, and liquid hydrogen shielding with areal density of $20 \mathrm{~g} / \mathrm{cm}^{2}$. Table 5 shows results for the $\chi^{2}$ statistic comparing polyethylene and hydrogen shielding effectiveness to aluminum. For calculations that ignore the low LET risk coefficient uncertainties, near solar maximum with a large SPE, significant results $(\mathrm{P}<0.01)$ are found for liquid hydrogen, and for the GCR at solar minimum (with $\mathrm{P}<0.15$ ). We conclude that because of the modest differences between polyethylene and aluminum as GCR absorbers, and the large radiobiological uncertainties in cancer risk projection models, the benefits of polyethylene compared to aluminum shielding for GCR can not be proven at this time. A key factor in these results is that although aluminum is a greater producer of secondary radiation compared to polyethylene, tissue shielding “equalizes” much of these differences.

The formalism can be applied to estimate the number of days a mission is ensured to be below an exposure limit at a given confidence level. Because we use the REID quantity, and the newer LSS Report 13 (Preston et al., 2003) values for ELR and EAR compared to the NCRP Report 132 (NCRP, 2000), and consider limits for single missions rather than 10-year careers, we first calculated dose limits that result for the present model corresponding to $3 \%$ and $5 \%$ fatal cancer risk for missions of length $<3$ yr. These are listed in Table 6, which also shows calculations of loss of life-expectancy (LLE) from radiation cancer induced cancers. In an earlier report (Cucinotta, et al. 2000b) we estimated the maximum number of days in deep space astronauts could spend with a 95\% CL to remain below a 3\% fatal cancer risk. Table 7 updates these calculations and compares to the earlier report. The results show a significant increase in the 
number of "safe" days with 95\% CL to remain below acceptable levels or risk that result from our improved methodology. However, the results are well short of that needed for a Mars mission.

\section{Discussion}

The building of PDF's that propagate errors from individual factors that contribute to uncertainties in projection models is a powerful tool for managing radiation risks, including evaluating benefits of research and mitigation approaches and implementing the radiation protection principle of as low as reasonable achievable (ALARA). The uncertainties estimated here are reduced compared to our previous estimates (Cucinotta et al., 2001b, 2002, 2004) for the following reasons:

1. Use of the REID rather than radiation cancer rates (decreases upper uncertainty level because of role of competing risks)

2. Use of trial $\mathrm{Q}(\mathrm{L})$ functions rather than uncorrelated uncertainties as a function of LET (overall decrease in uncertainties)

3. Neglect of NCRP “unknown” uncertainties (decrease in uncertainties)

4. Re-defining LET-spectra uncertainties (modest increase in uncertainties). However, these estimates should be viewed as preliminary because of the need to assess additional uncertainties that have not been included in the analysis, including protraction effects, scaling of ERR's or EAR's estimated from low LET data to high LET's, and the potential impact of a healthy worker effect. These factors will need to be considered in future work. Low-LET epidemiology data and physics models uncertainties have a smaller role in the present evaluation. As noted in our earlier report (Cucinotta et al., 2001b), other uncertainties exist in the representation of radiation shielding composition and predicting future solar cycle effects or the characteristics of SPE's; however these are more practical in nature and will be considered elsewhere.

The methodologies used for risk assessment ultimately play a large role in the estimates of uncertainties and shielding effectiveness. The use of the linear-additivity model is a key assumption in the current methodology. This model has a strong basis in mouse carcinogenesis studies with low dose neutron irradiations (Storer and Fry, 1995), and for neutron exposures, a mixed low and high-LET field is present due to the gamma-rays produced by neutrons. Possible deviations from the linear-additivity model for the GCR spectrum along with correlations in estimates of DDREF, protraction effects and quality factors need to be considered in future work. 
Experiments that simulate the constant high-energy proton background with interspersed heavy nuclei irradiation such as iron would be a first-step in testing these effects. Further investigation of alternative methodologies that could possibly reduce uncertainty estimates should also be considered. However, the need for new biological data and understanding is the most important approach to reducing uncertainties.

We have not made an estimate of the uncertainties based on radiation quality effects related to latency, time after exposure, or exposure protraction. The model of Eq.'s (1)-(5) assumes implicitly that these factors are independent of radiation quality. For low dose-rate and protracted proton and HZE radiation exposure of more than a few months, new biological factors may influence risk assessments including redistribution in the cell cycle, repopulation, or promotional effects, especially when particle fluences are large enough to lead to multiple hits of target cells or surrounding cells and tissue environments. Also, not only is there no human data for protons and HZE ions, there is very little experimental data at low dose-rates for these particles. Experimental data for protracted proton or heavy ion irradiation in experimental models of carcinogenesis is almost non-existent. Burns et al. (1994) found split doses of argon ions separated by a few hours up to one-day increased the risk of skin cancer in rats. Alpen et al. (1994) found using seven two-week fractions of 0.07 Gy of iron an increase in risk of 50\% compared to a single acute dose of $0.4 \mathrm{~Gy}$ for Harderian gland tumors in mice. A study of chromosomal aberrations in human lymphocytes (George et al., 2001) for acute and low dose-rates $(0.08 \mathrm{~Gy} / \mathrm{hr})$ with $250 \mathrm{MeV}$ protons, showed less sparring than found for gamma-rays. The Skyhook study of Ainsworth et al. (1986) considered life-shortening in mice comparing single acute with weekly fractions of several ions, however the results were unclear with regards to any increase or decrease in risk. For gamma-rays and neutrons, a good number of studies for cancer induction or life-shortening in mice exists, showing sparring effects for gamma-rays, and that neutron effects may be increased due to protraction under certain conditions in some tissues (Ullrich, 1984; NCRP, 1990). Important questions related to the differences in life-span, cell turn-over rates, or mechanisms of initiation or promotion in humans and mice, make estimates of the effects of protraction on risk difficult. Data on tumors or genomic instability in mice with neutrons (Ullrich et al., 1984; 1998; NCRP, 1990) and the studies of rat or mammary 
carcinogenesis with HZE nuclei (Burns, et al., 1994; Dicello et al., 2004), suggest that the latency time is appreciably reduced for high LET compared to low LET radiation. In the model described above, a radiation quality dependent latency is more important in the additive transfer model than the multiplicative transfer model, especially at younger ages of exposure.

Career radiation limits and shielding requirements could also be impacted by new knowledge of fatal non-cancer risks from radiation exposure such as heart disease (Preston et al., 2003; Howe et al., 2004; Yang et al., 1982) or damage to the central nervous system (CNS). Based on the Japanese survivor data (Preston et al., 2003), non-cancer risks are estimated to be small for the shorter lunar missions, but could lead to a significant risk for the Mars mission. The risk of heart disease for ions is largely unknown because only one report (considered a pilot study by the authors of the report) has been made on the effects of HZE ions on heart disease (Yang et al., 1982), and human data for low LET radiation at low dose-rates is inconclusive on the level of risk to be expected (Howe et al., 2004; Cardis et al., 1995). CNS risks have the potential to impact both short-term and career radiation limits and mitigation approaches (NRC, 1996).

We have shown that with regard to the GCR, the optimization of material selection and mass can not be put on a sound scientific basis because the reductions estimated from point estimates alone are only on the order of a $10-30 \%$ for most shielding materials, and when combined with the uncertainties in projection models non-significant results for risk reduction are found. It still may be reasonable to assume that risk is reduced when comparing hydro-carbon shields to aluminum or other metals, however application of ALARA is problematic since costbenefit analysis can not be properly performed under these conditions. In contrast, for acute risks, which are largely an absorbed dose and dose-rate effect, SPE's are the major concern and the role of minimizing mass requirements through hyrdo-carbon shielding materials is easier to prove.

The ALARA principle is an important aspect of radiation safety. Our estimate of $95 \%$ CL's to stay below limits can be used as criteria for a minimal ALARA requirement for the design of lunar missions including transfer vehicle or surface habitat designs. For example about a 4-fold margin can be used for GCR exposures and about a 2.5 fold margin for SPE's. Detailed cost-benefit analysis should be used for measures that would provide even lower risks. Future work should consider a worst-case SPE environment including the possibility of multiple SPE's as a function of mission duration. Based on the results of Table 7 and the above margins, we 
conclude that "blind selection" of astronauts for lunar missions can be made for missions with duration less than 120 days for male or female astronauts above the age of 35-yrs, if sufficient protection against SPE's is provided. Because of the higher GCR risks for the longer Mars missions or perhaps long-term lunar missions, and the likely impacts of non-cancer risks, no conclusions on ALARA goals for these missions or the possibility of "blind selection" can be made at this time. The inherent uncertainties in population based risk models and the higher risks; point to the likelihood that individual based risk assessments will be needed for Mars exploration missions.

\section{Acknowledgement}

We note our appreciation for useful discussions with Dr. Walter Schimmerling

\section{References}

Ainsworth, E.J., 1986. Early and Late Mammalian Responses to Heavy Charged Particles. Adv. in Space Res. 6, 153-162.

Alpen, E.L., Powers-Risius, P, Curtis, S.B., and DeGuzman, R., 1993. Tumorigenic Potential of High-Z, High-LET Charged Particle Radiations. Radiat. Res. 88, 132-143.

Alpen, E.L., Powers-Risius, P., Curtis, S.B., DeGuzman, R., and Fry, R.J.M., 1994. FluenceBased Relative Biological Effectiveness for Charged Particle Carcinogenesis in Mouse Harderian Gland. Adv. Space. Res. 14(10), 573-581.

Badhwar, G.D., and O’Neill, P.M., 1994a. Long-term Modulation of Galactic Cosmic Radiation and Its Model for Space Exploration. Adv. Space. Res. 14(10), 749-757.

Badhwar, G.D., Cucinotta, F.A., and O'Neill, P.M., 1994b. An Analysis of Interplanetary Space Radiation Exposure for Various Solar Cycles. Radiat. Res. 138, 201-208.

Badhwar, G.D, 1997. Spaceflight Validation of Material Shielding Properties. In: NASA Workshop on Shielding Strategies for Human Space Exploration. Eds. Wilson, J.W., Miller, J., Konradi, A., and Cucinotta, F.A. NASA-CP-1997-3360.

Badhwar, G.D., Cucinotta, F.A., 2000. A Comparison of Depth Dependence of Dose and Linear Energy Transfer Spectra in Aluminum and Polyethylene. Radiat. Res. 153, 1-8.

Belli M., Cera F., Cherubini, R., Haque, A.M.I., Ianzini, F., Moschini, G., Sapora, O., Simone, G. Tabocchini, M.A., Tiverton, P., 1993. Inactivation and Mutation Induction In V79 Cells by Low Energy Protons: Re-evaluation of the results at the LNL facility. Int. J. Radiat. Biol. 63, 331-337.

Benton E.R., Benton, E.V., and Frank, A.L., 2002. Passive Dosimetry Aboard the Mir Orbital Station: Internal Measurements. Radiat. Meas. 35, 439-456. 
Billings, M.P., Yucker, W.R., and Heckman, B.R., 1973. Body Self-Shielding Data Analysis, McDonald Douglas Astronautics Company West, MDC-G4131.

Bunger, B.M., Cook, J.R., and Barrick, M.K., 1981. Life Table Methodology for Evaluating Radiation Risk: An Application Based On Occupational Exposures. Health Phys. 40, 439-455.

Burns F., Yin Y., Garte, S.J., and Hosselet, S., 1994. Estimation of Risk Based on Multiple Events in Radiation Carcinogenesis of Rat Skin. Adv. Space Res. 14, 507-519.

Cardis, E., Gilbert, E.S., Carpenter, L. Howe, G. Kato, I., Armstrong, B.K. Beral, V. Cowper, G. Douglas, A. Fix, J. Fry, S.A., Kaldor, J., Lavé, C. Salmon, L., Smith, P.G. Voelz, G.L. and Wiggs, L.D., 1995. Effects of Low Doses and Dose-Rates of External Ionizing Radiation: Cancer Mortality Among Nuclear Industry Workers In Three Countries. Radiat. Res. 142, 117-132.

Center for Disease Control (CDC) National Vital Statistics Report, Vol. 51, No. 3, US Life Tables, 2000, 2002.

Committee on the Biological Effect of Ionizing Radiation (BEIR) BEIR V, 1994.

Cox, R., and Masson, W.K., 1979. Mutation and Inactivation of Cultured Mammalian Cells Exposed To Beams of Accelerated Heavy Ions. Int. J. Radiat. Biol. 36, 149-160.

Cucinotta, F.A., Wilson J.W., Shavers M.R., and Katz, R., 1996. Effects of Track Structure and Cell Inactivation on the Calculation of Heavy Ion Mutation Rates in Mammalian Cells. Int. J. Radiat. Biol. 69, 593-600.

Cucinotta, F.A., Wilson, J.W., Shinn, J.L., and Tripathi, R.K., 1998a. Assessment and Requirements of Nuclear Reaction Data Bases for GCR Transport in the Atmosphere and Structures. Adv. in Space. Res. 21, 1753-1762.

Cucinotta, F.A., Nikjoo, H., and Goodhead, D.T., 1998b. The Effects of Delta Rays on The Number of Particle-Track Traversals per Cell in Laboratory and Space Exposures. Radiat. Res. 150, 115-119.

Cucinotta, F.A., Wilson, J.W., Williams, J.R., and Dicello, J.F., 2000. Analysis Of Mir-18 Results for Physical And Biological Dosimetry: Radiation Shielding Effectiveness In LEO. Radiat. Meas. 31.

Cucinotta, F.A., Manuel, F., Jones, J., Izsard G., Murray, J., Djojonegoro B., and Wear M., 2001a. Space Radiation and Cataracts in Astronauts. Radiat. Res. 156, 460-466.

Cucinotta, F.A., Schimmerling, W., Wilson, J.W., Peterson, L.E., Saganti, P., Badhwar, G.D., and Dicello, J.F., 2001b. Space Radiation Cancer Risks and Uncertainties for Mars Missions. Radiat. Res. 156, 682-688.

Cucinotta, F.A., Badhwar, G.D., Saganti, P., Schimmerling, W., Wilson, J.W., Peterson, L., and Dicello, J., 2002. Space Radiation Cancer Risk Projections for Exploration Missions, Uncertainty Reduction and Mitigation. NASA TP-2002-210777.

Cucinotta, F.A., Saganti, P.B., Hu, X., Kim, M-H. Y., Cleghorn, T.F., Wilson, J.W., Tripathi, 
R.K., and Zeitlin, C.J., 2003. Physics of the Isotopic Dependence of Galactic Cosmic Ray Fluence Behind Shielding. NASA TP-2003-210792.

Cucinotta, F.A., Schimmerling, W., Wilson, J.W., Peterson, L.E., and Saganti, P.B., 2004. Uncertainties In Estimates Of The Risks of Late Effects From Space Radiation. Adv. Space Res. 32, 1383-1389.

Dicello, J.F., Cucinotta, F.A., Gridley, D., Mann, J., Moyers, M. F., Novak, G. R., Piantadosi, S., Ricart-Arbona, R., Simonson, D. M., Strandberg, J.D., Vazquez, M., Williams, J.R., Zhang, Y., Zhou, H., and Huso, D., 2004. In vivo Mammary Tumorigenesis in the Sprague-Dawley Rat and Microdosimetric Correlates. Phys. Med. Biol. 49, 3817-3830.

Fry, R.J.M., Powers-Risius, P., Alpen, E.L., Ainsworth, E.J., 1985. High LET Radiation Carcinogenesis. Radiat. Res. 104, S188-195.

George, K., Willingham, V., Wu, H., Gridley, D., Nelson, G., and Cucinotta, F.A., 2002. Chromosome Aberrations in Human Lymphocytes Induced By $250 \mathrm{MeV}$ Protons: Effects of Dose, Dose Rate and Shielding. Adv. Space Res. 30, 891-899.

George, K., Durante, M., Willingham, V., Wu, H., Yang, T., and Cucinotta, F.A., 2003. Biological Effectiveness of Accelerated Particles for the Induction of Chromosome Damage Measured in Metaphase and Interphase Human Lymphocytes. Radiat. Res. 160, 425-435.

Howe, G.R., Zablotska, L.B., Fix, J.J., Egel, J, Buchanan, J., 2004. Analysis of the Mortality Experience amongst U.S. Nuclear Power Industry Workers after Chronic Low-Dose Exposure to Ionizing Radiation. Radiat. Res. 162, 517-526.

International Commission on Radiation Protection, 2003. ICRR Publication 92, Relative Biological Effectiveness (RBE), Quality Factor (Q), and Radiation Weighting Factor $\left(\mathrm{w}_{\mathrm{R}}\right)$, Pergamon.

International Commission on Radiation Units, 1986. The Quality Factor in Radiation Protection, ICRU Report 40, ICRU Publications, Bethesda MD.

Katz, R., Ackerson, B., Homayoonfar, M., and Scharma, S.C., 1971. Inactivation of Cells by Heavy Ion Bombardment. Radiat. Res. 47, 402-425.

Kawata, T., Durante, M., Furusawa, Y., George, K., Takai, N., Wu, H., and Cucinotta, F.A., 2001. Dose Response of Initial G2-Chromosomal Damage Induced in Normal Human Fibroblasts by High-LET Particles. Int. J. Radiat. Biol. 77, 165-174.

Kiefer, J., Stoll, U., Schneider, E., 1994. Mutation Induction by Heavy Ions. Adv. Space Res. 14(10), 257-265.

Kim, M.Y., Barber, R.E., Shavers, M.R., Nikjoo, H., and Cucinotta, F.A., 2003. TEPCs Overestimate the Average Quality Factor for Trapped Protons and Underestimate the Average Quality Factor for GCR. Presented at the $14^{\text {th }}$ Annual Space Radiation Health Investigators Workshop.

Kronenberg, A., 1994. Mutation Induction in Human Lymphoid Cells by Energetic Heavy Ions. Adv. Space Res. 14(10), 339-346. 
Martin, S.G., Miller, R.C., Geard, C.R., Hall, E.J., 1995. The Biological Effectiveness Of RadonProgeny Alpha Particles. IV. Morphological Transformation of Syrian Hamster Embryo Cells at Low Dose. Radiat. Res. 142, 70-77.

Miller, R.C., Marino, S.A., Brenner, D.J., Martin, S.G., Richards, M., Randers-Pehrson, G., Hall, E.J., 1995. The Biological Effectiveness of Radon-Progeny Alpha Particles III. Quality Factors. Radiat. Res. 142, 61-69.

National Academy of Sciences, NAS. National Academy of Sciences Space Science Board, Report of the Task Group on the Biological Effects of Space Radiation. Radiation Hazards to Crews on Interplanetary Mission National Academy of Sciences, Washington, D.C., 1996.

National Council of Radiation Protection and Measurements, NCRP. Relative Biological Effectiveness of Radiations of Different Quality, NCRP Report 104, Bethesda MD, 1990.

National Council on Radiation Protection and Measurements, NCRP. Uncertainties in Fatal Cancer Risk Estimates Used in Radiation Protection, NCRP Report 126, Bethesda MD, 1997.

National Council on Radiation Protection and Measurements, NCRP. Recommendations of Dose Limits for Low Earth Orbit. NCRP Report 132, Bethesda MD, 2000.

Nelson, G.A., Schubert, W.W., Marshall, T.M., Benton, E.R., Benton, E.V., 1989. Radiation effects in Caenorhabditis Elegans, Mutagenesis by High and Low LET Ionizing Radiation. Mut. Res. 212, 181-192.

Nikjoo, H., O’Neill, P., Terrissol, M., and Goodhead, D.T., 1999. Quantitative Modeling of DNA Damage Using Monte Carlo Track Structure Method. Radiat. Envir. Biophys. 38, 31-38.

Nikjoo, H., Khvostunov, I.K., and Cucinotta, F.A., 2002. The Response of (TEPC) Proportional Counters to Heavy Ions. Radiat. Res. 157, 435-445.

O’Neill, P., Badhwar, G.D., 2005. Galactic Cosmic Ray Model Update Based on Advanced Composition Explorer (ACE) Spectra from 1997 to Present. Adv. Space Res (in press).

Parker, E.N., 1965. The Passage of Energetic Charged Particles Through Interplanetary Space. Planet. Space Sci. 13, 9-49.

Pierce, D.A., Shimizu, Y., Preston, D.L., Vaeth, M., and Mabuchi, K., 1996. Studies of the Mortality of The Atomic-Bomb Survivors, Report 12, Part I. Cancer: 1950-1990. Radiat. Res. $146,1-27$.

Preston, D.L., Shimizu, Y., Pierce, D.A., Suyumac, A., and Mabuchi, K., 2003. Studies of Mortality of Atomic Bomb Survivors. Report 13: Solid Cancer and Noncancer Disease Mortality: 1950-1997. Radiat. Res. 160, 381-407.

SEER, Surveillance, Epidemiology, and End Results: Cancer Statistics Review, 1973-2000. Cancer Surveillance Research Program, National Cancer Institute, Bethesda MD, 2000.

Shinn, J.L., Cucinotta, F.A., Simonsen, L.C., Wilson, J.W., Badavi, F.F., Badhwar, G.D., 
Miller, J., Zeitlin, C. R.K., Clowdsley, M.S., Heinbockel, J.H., and Xapsos, M.A., 1998.

Validation of a Comprehensive Space Radiation Transport Code. IEEE Nuclear Sci. 45, 27112719.

Storer, J.B., and Fry, R.J.M., 1995. Limiting Values of RBE of Fission Neutrons at Low Doses for Life-Shortening in Mice. Radiat. Environ. Biophys. 34, 21-27.

Ullrich, R.L., 1984. Tumor Induction in BAL/c Mice after Fractionated Neutron or Gamma Irradiation. Radiat. Res. 93, 506-512.

Ullrich, R.L., and Ponnaiya B., 1998. Radiation-Induced Instability and Its Relation to Radiation Carcinogenesis. Inter. J. Radiat. Biol. 74, 747-754.

Vaeth, M., and Pierce, D.A., 1990. Calculating Excess Lifetime Risk in Relative Risk Models. Environ. Health Per. 87, 83-94.

Wilson J.W., Townsend, L.W., Schimmerling, W., Khandelwal, G.S., Khan, F., Nealy, J.E., Cucinotta, F.A., Simonsen, L.C., and Norbury, J.W., 1991. Transport Methods and Interactions for Space Radiations. RP1257, NASA, Washington D.C.

Wilson, J. W., Kim, M., Schimmerling, W., Badavi, F. F., Thibeault, S. A., Cucinotta, F. A., Shinn, J. L., and Kiefer, R., 1995. Issues in Space Radiation Protection. Health Phys. 68, 50-58.

Yang, V.V., and Ainsworth, E.J., 1982. Late Effects of Heavy Charged Particles on the Fine Structure of the Mouse Coronary Artery. Radiat. Res. 91, 135-144.

Yang, T.C., Craise, L.M., Mei, M., and Tobias, C.A., 1989. Neoplastic Transformation by High LET Radiation: Molecular Mechanisms. Adv. Space. Res. 9, 131-140. 


\section{Figure Captions}

Figure 1. Comparison of ratio of $R B E_{\max }$ to $Q$ for several endpoints found with proton, alpha particle, and heavy ion irradiations (Reference to experiments listed in Table I).

Figure 2a. Examples of trial quality factor functions used in uncertainty calculations. A distinct curve is generated for each trial.

Figure 2b. Average quality factor (circles) and 95\% CI's versus LET that from MonteCarlo sampling over trial function of Eq. (7).

Figure 3. PDF for GCR effective dose for $20 \mathrm{~g} / \mathrm{cm}^{2}$ aluminum shield for 600-d Mars swing-by mission. The point estimate is $0.86 \mathrm{~Sv}$, and the 95\% CI for uncertainties in LET distribution at tissue sites is $[0.78,1.08]$ Sv. Only uncertainties in physics are included.

Figure 4. Point dose equivalent (upper panel) and effective dose (bottom panel) behind various shields for solar minimum GCR and August 1972 SPE (the units for the SPE doses are for total event and not necessarily per year).

Figure 5. Calculations of REID versus LET at doses of 0.01 or 0.1 Gy for 40-y males. Diamonds point estimates, bands 95\% CI, and squares the fold uncertainties.

Figure 6. PDF's for 40-y males for a 600-day Mars swing-by mission for $20 \mathrm{~g} / \mathrm{cm}^{2}$ shields of aluminum, polyethylene or liquid hydrogen. Effective doses, and point estimates and 95\% CI for REID are shown in box. 
Figure 1

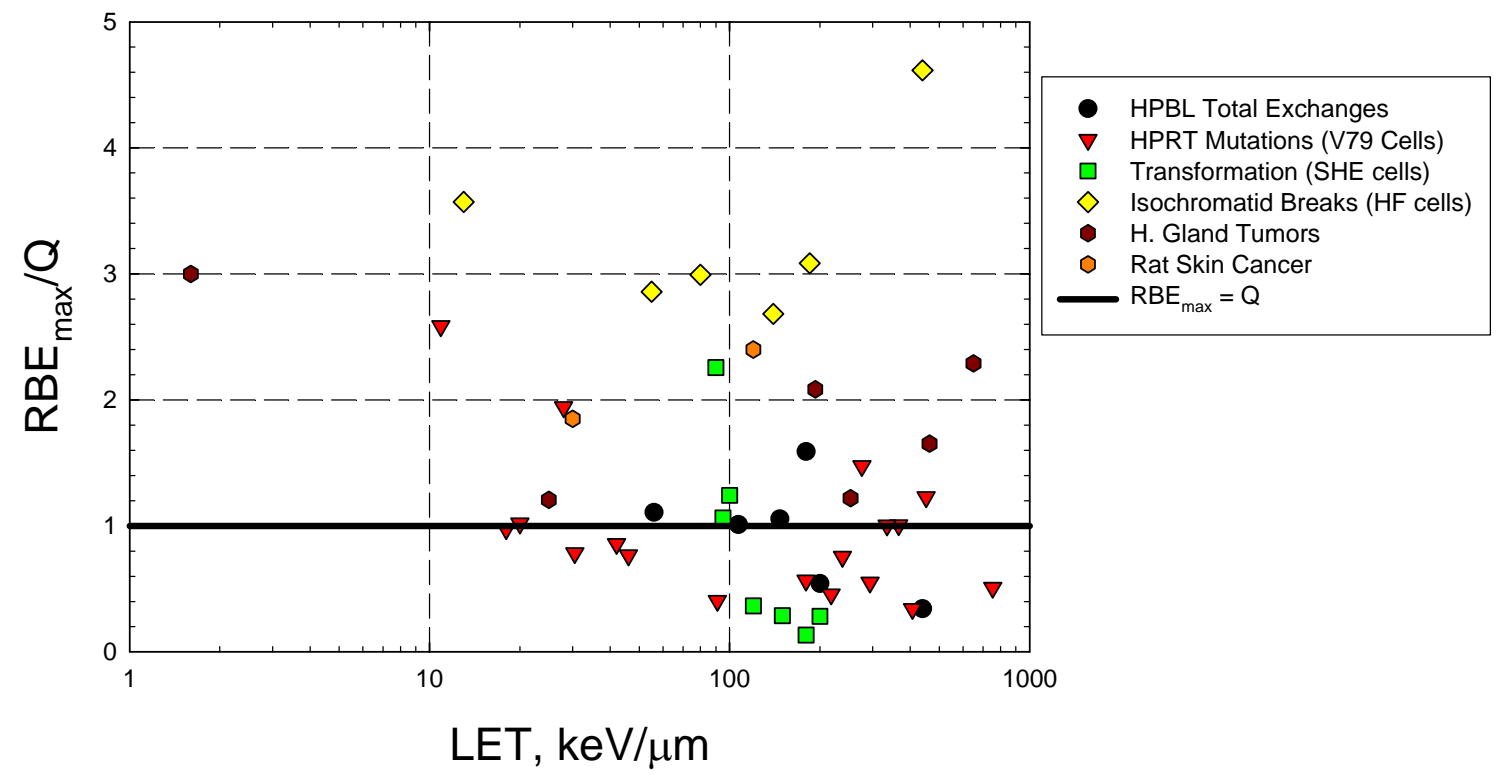


Figure 2
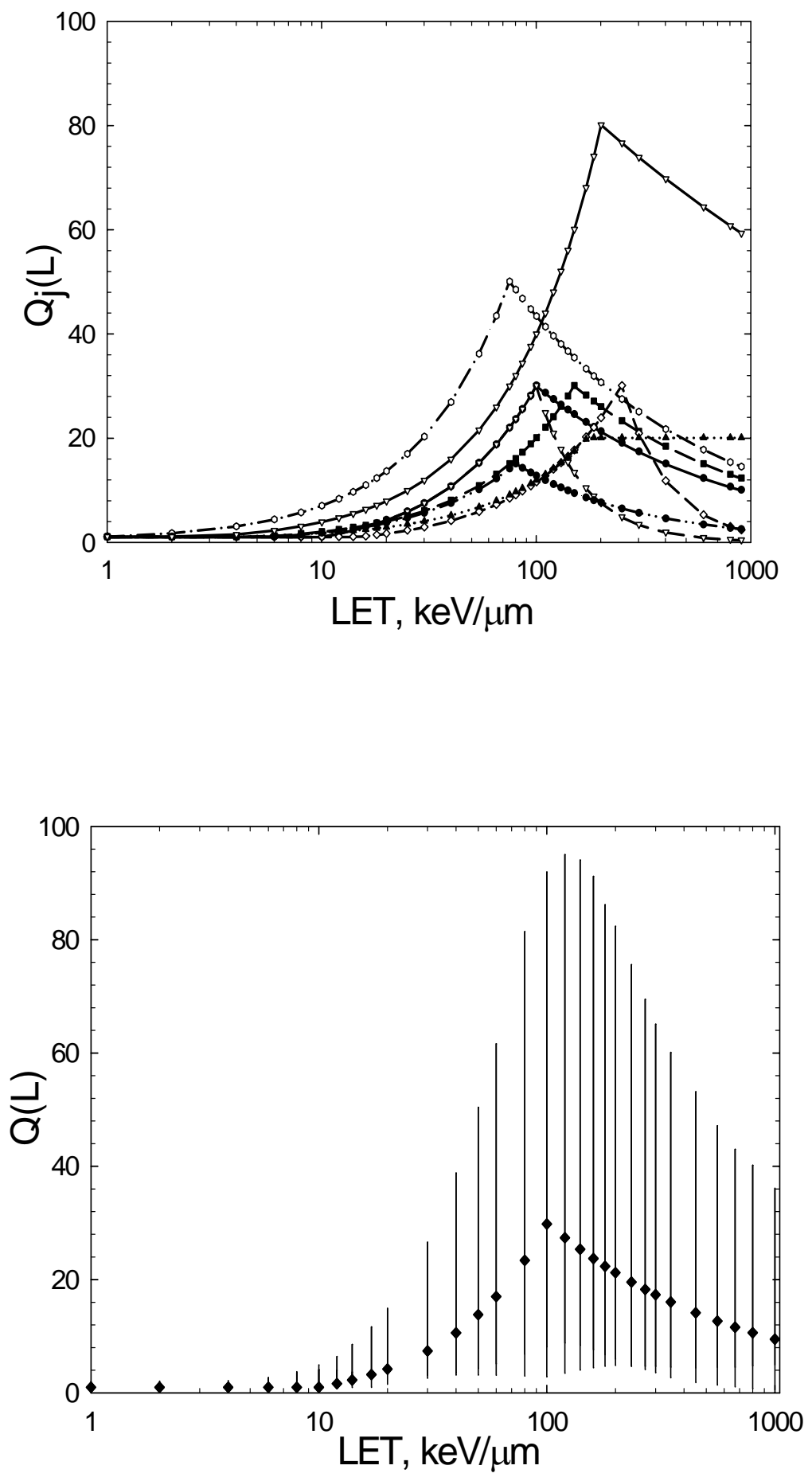
Figure 3

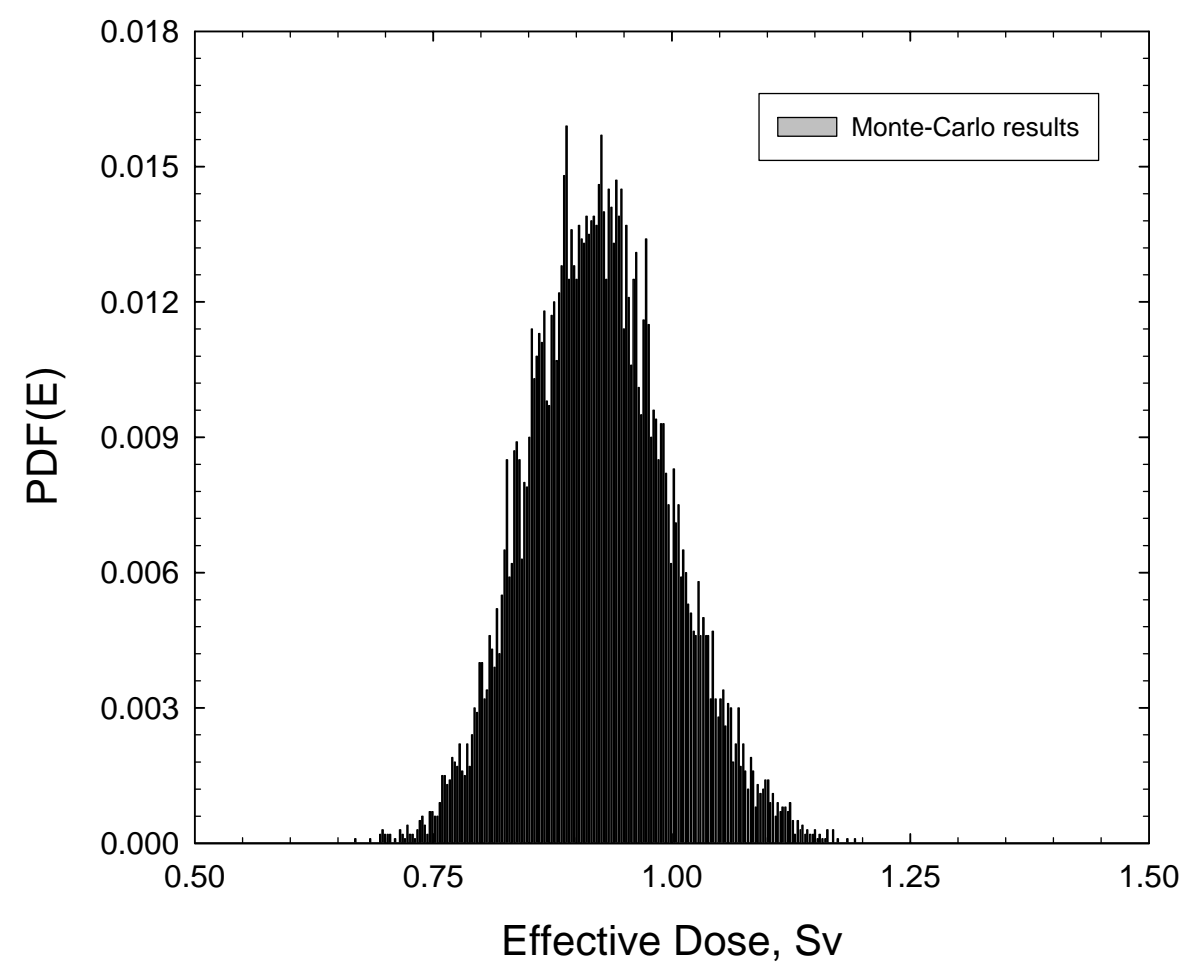




\section{Figure 4}

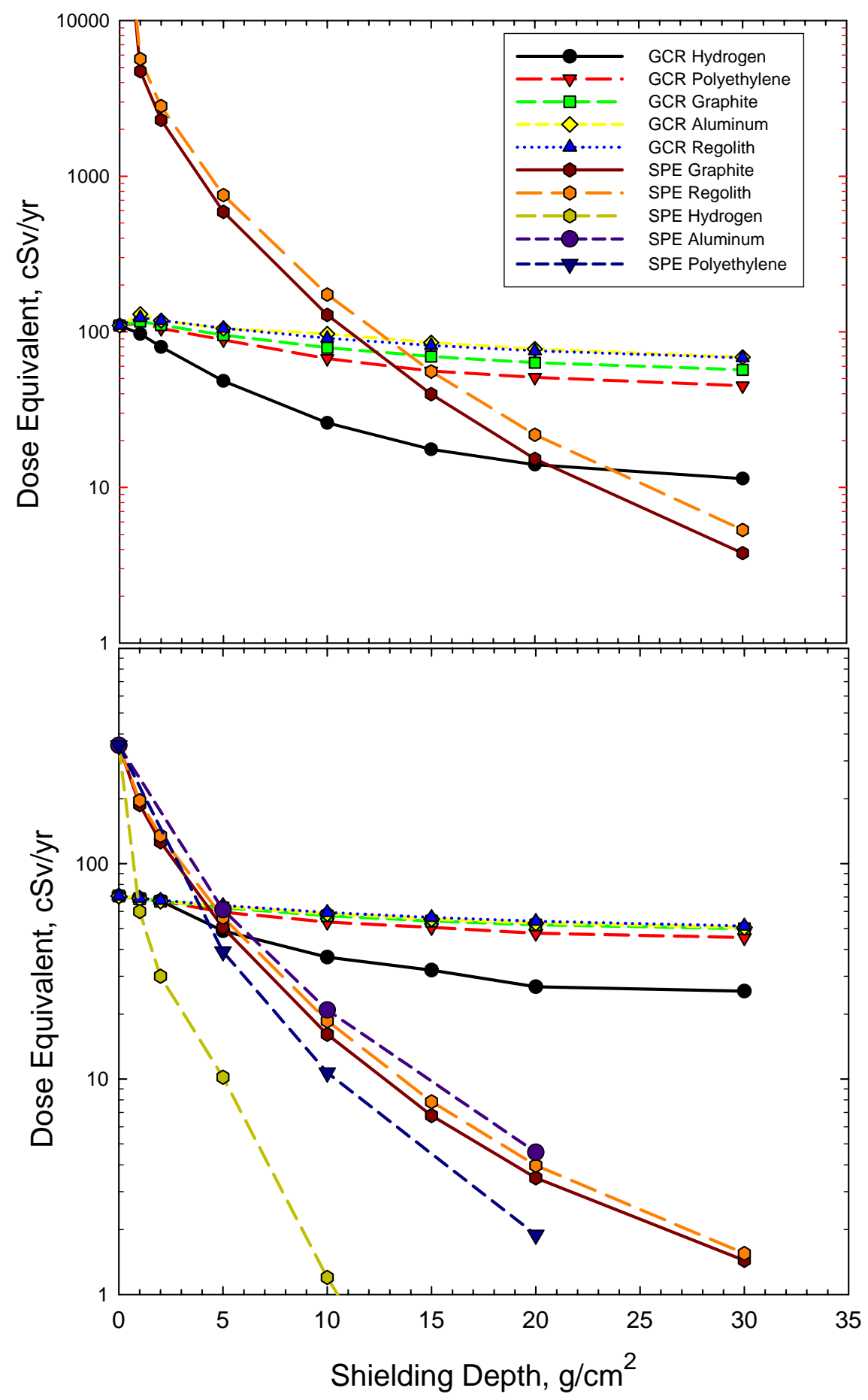


Figure 5
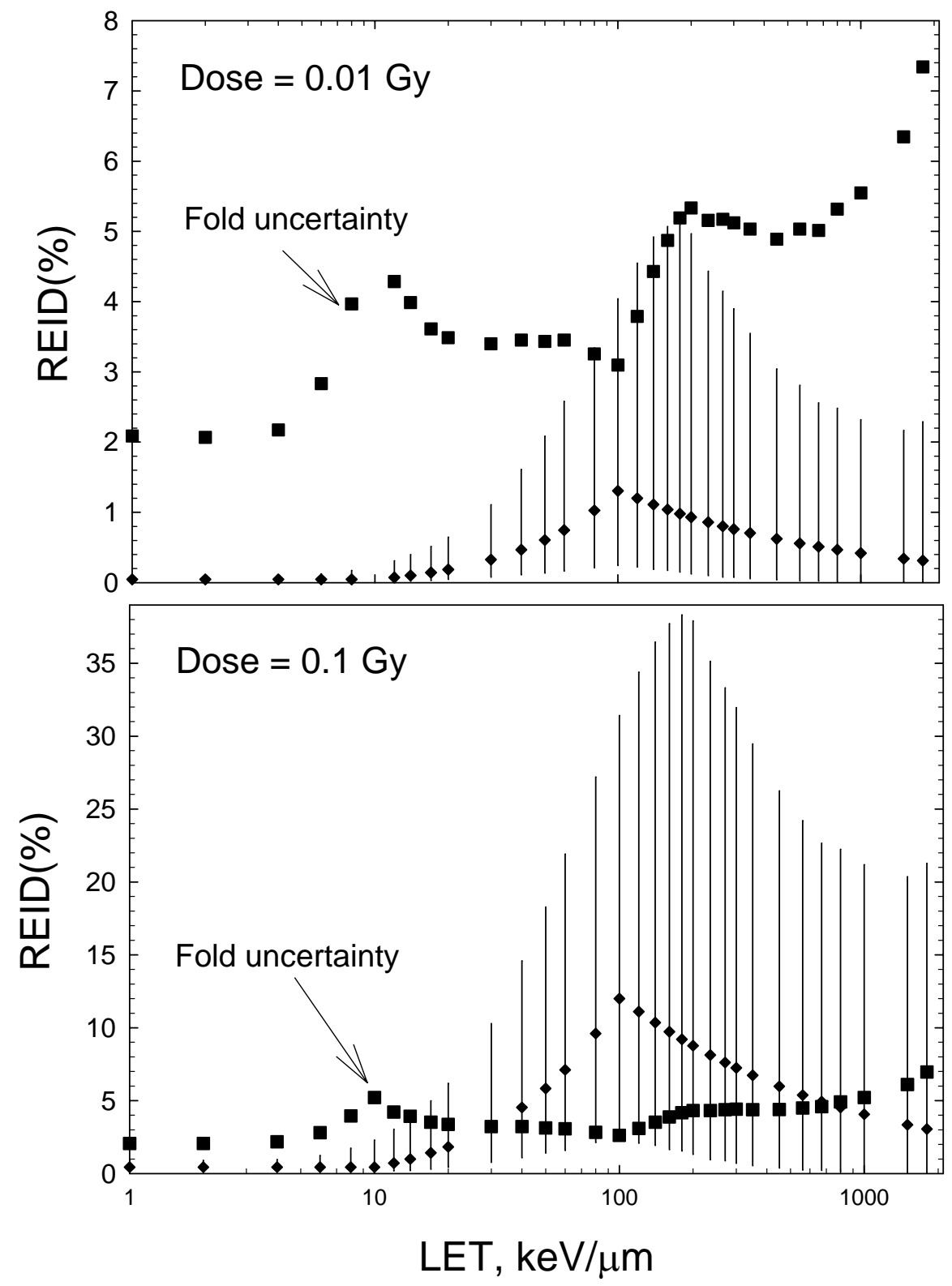


\section{Figure 6}

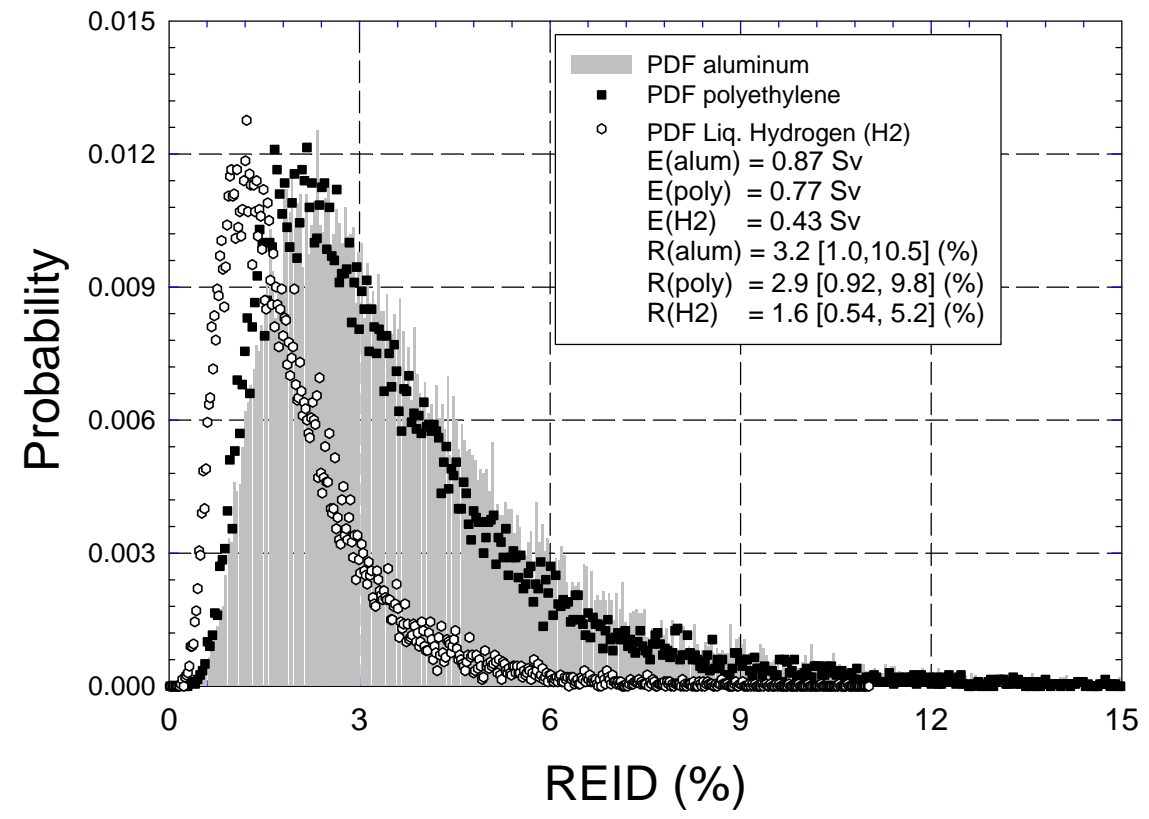


Table 1. Approximate LET where maximum RBE was found in biological experiments.

\begin{tabular}{|c|c|c|c|c|}
\hline Biological system & Endpoint & $\begin{array}{l}\text { LET at peak } \\
R B E, \mathrm{keV} / \mu \mathrm{m}\end{array}$ & $\begin{array}{l}\text { LET range (No. of } \\
\text { ions studied) }\end{array}$ & Reference \\
\hline $\begin{array}{l}\text { Human TK6 } \\
\text { lymphoblasts cells }\end{array}$ & TK mutants & 60 & $32-190(6)$ & Kronenberg (1994) \\
\hline $\begin{array}{l}\text { Human TK6 } \\
\text { lymphoblasts cells }\end{array}$ & HPRT mutants & 60 & $32-190(6)$ & Kronenberg (1994) \\
\hline $\begin{array}{l}\text { Human lung } \\
\text { fibroblasts }\end{array}$ & HPRT mutants & 90 & $20-470(9)$ & $\begin{array}{l}\text { Cox and Masson } \\
\text { (1979) }\end{array}$ \\
\hline $\begin{array}{l}\text { Human Skin } \\
\text { fibroblasts }\end{array}$ & HPRT mutants & 150 & $25-920(7)$ & $\begin{array}{l}\text { Tsuoboi et al. } \\
\text { (1992) }\end{array}$ \\
\hline $\begin{array}{l}\text { V79 Chinese } \\
\text { hamster cells }\end{array}$ & HPRT mutants & 90 & $10-2000$ (16) & $\begin{array}{l}\text { Kiefer et al. (1994); } \\
\text { Belli et al. (1993) }\end{array}$ \\
\hline $\begin{array}{l}\text { Caenorhabditis } \\
\text { elegans }\end{array}$ & $\begin{array}{l}\text { Recessive } \\
\text { lethal } \\
\text { mutations }\end{array}$ & 190 & $0.55-1110(14)$ & Nelson et al. (1989) \\
\hline $\begin{array}{l}\text { Human } \\
\text { lymphocyte cells }\end{array}$ & $\begin{array}{l}\text { Chromosomal } \\
\text { exchanges }\end{array}$ & 147 & 0.4-1000 (10) & $\begin{array}{l}\text { George et al. } \\
(2003)\end{array}$ \\
\hline $\begin{array}{l}\text { Human fibroblast } \\
\text { cells }\end{array}$ & $\begin{array}{l}\text { Chromatid } \\
\text { breaks }\end{array}$ & 80-185 & $13-440(6)$ & $\begin{array}{l}\text { Kawata et al. } \\
(2001)\end{array}$ \\
\hline $\begin{array}{l}\text { C3H10T1/2 mouse } \\
\text { cells }\end{array}$ & Transformation & 140 & $10-2000(10)$ & Yang et al. (1989) \\
\hline $\begin{array}{l}\text { C3H10T1/2 mouse } \\
\text { cells }\end{array}$ & Transformation & 90 & $20-200(10)$ & Miller et al. (1995) \\
\hline $\begin{array}{l}\text { Syrian hamster } \\
\text { embryo (SHE) } \\
\text { cells }\end{array}$ & Transformation & 90 & $20-200(8)$ & Martin et al. (1995) \\
\hline Mouse $\left(\mathrm{B} 6 \mathrm{CF}_{1}\right)$ & $\begin{array}{l}\mathrm{H} . \text { gland } \\
\text { tumors }\end{array}$ & $185^{\star}$ & $2-650(6)$ & Fry et al. (1985) \\
\hline Mouse $\left(B 6 C F_{1}\right)$ & $\begin{array}{l}\text { H. gland } \\
\text { Tumors }\end{array}$ & 193 & $0.4-1000(7)$ & Alpen et al. (1993) \\
\hline Mouse $\left(\mathrm{CB} \mathrm{F}_{1}\right)$ & Days life lost & $52^{*}$ & $50-500(6)$ & Ainsworth (1986) \\
\hline
\end{tabular}

*Track-segment or spread-out Bragg peak (SOBP) irradiations.

Table 2. Standard deviations for uncertainties in model LET spectra for several LET regions.

\begin{tabular}{l|l}
\hline LET Interval & S.D. for $d F / d L$ \\
\hline$<30 \mathrm{keV} / \mu \mathrm{m}$ & 1.0 \\
$30-300 \mathrm{keV} / \mu \mathrm{m}$ & 2.0 \\
$>300 \mathrm{keV} / \mu \mathrm{m}$ & 2.5 \\
\hline
\end{tabular}


Table 3a. Calculations of effective doses, REID, and 95\% CI for lunar or Mars missions. Calculations are at solar minimum for a $5-\mathrm{g} / \mathrm{cm}^{2}$ aluminum shield

\begin{tabular}{|c|c|c|c|c|}
\hline $\begin{array}{l}\text { Exploration } \\
\text { mission }\end{array}$ & $D, G y$ & $E, S V$ & $R E I D(\%)$ & $95 \% \mathrm{Cl}$ \\
\hline & & \multicolumn{3}{|c|}{ Males (40 y) } \\
\hline Lunar-long & 0.03 & 0.084 & 0.34 & {$[0.10,1.2]$} \\
\hline $\begin{array}{l}\text { Mars } \\
\text { swingby }\end{array}$ & 0.37 & 1.03 & 4.0 & {$[1.0,13.5]$} \\
\hline \multirow{2}{*}{$\begin{array}{l}\text { Mars } \\
\text { surface }\end{array}$} & 0.42 & 1.07 & 4.2 & {$[1.3,13.6]$} \\
\hline & & \multicolumn{3}{|c|}{ Females (40 y) } \\
\hline Lunar-long & 0.03 & 0.084 & 0.41 & {$[0.12,1.5]$} \\
\hline $\begin{array}{l}\text { Mars } \\
\text { swingby }\end{array}$ & 0.37 & 1.03 & 4.9 & {$[1.4,16.2]$} \\
\hline $\begin{array}{l}\text { Mars } \\
\text { surface }\end{array}$ & 0.42 & 1.07 & 5.1 & {$[1.6,16.4]$} \\
\hline
\end{tabular}

Table 3b. Calculations of effective doses, REID, and 95\% $\mathrm{Cl}$ for lunar or Mars missions. Calculations are at solar minimum for a $20-\mathrm{g} / \mathrm{cm}^{2}$ aluminum shield

\begin{tabular}{|c|c|c|c|c|}
\hline $\begin{array}{l}\text { Exploration } \\
\text { mission }\end{array}$ & $D, G y$ & $E, S v$ & $R E I D(\%)$ & $95 \% \mathrm{Cl}$ \\
\hline & & \multicolumn{3}{|c|}{ Males (40 y) } \\
\hline Lunar-long & 0.03 & 0.071 & 0.28 & {$[0.09,0.95]$} \\
\hline $\begin{array}{l}\text { Mars } \\
\text { swingby }\end{array}$ & 0.36 & 0.87 & 3.2 & {$[1.0,10.4]$} \\
\hline \multirow{2}{*}{$\begin{array}{l}\text { Mars } \\
\text { surface }\end{array}$} & 0.41 & 0.96 & 3.4 & {$[1.1,10.8]$} \\
\hline & & \multicolumn{3}{|c|}{ Females (40 y) } \\
\hline Lunar-long & 0.03 & 0.071 & 0.34 & {$[0.11,1.2]$} \\
\hline $\begin{array}{l}\text { Mars } \\
\text { swingby }\end{array}$ & 0.36 & 0.87 & 3.9 & {$[1.2,12.7]$} \\
\hline $\begin{array}{l}\text { Mars } \\
\text { surface }\end{array}$ & 0.41 & 0.96 & 4.1 & {$[1.3,13.3]$} \\
\hline
\end{tabular}


Table 4a. Calculations of effective doses, REID, and 95\% $\mathrm{Cl}$ for lunar or Mars missions. Calculations are near solar maximum assuming 1972 SPE in deep space segment of mission with a $5-\mathrm{g} / \mathrm{cm}^{2}$ aluminum shield

\begin{tabular}{ccccc}
\hline $\begin{array}{c}\text { Exploration } \\
\text { mission }\end{array}$ & $D, G y$ & $E, S V$ & $R E I D(\%)$ & $95 \% \mathrm{Cl}$ \\
Lunar-long & 0.45 & 0.69 & 2.7 & {$[0.95,7.6]$} \\
$\begin{array}{c}\text { Mars } \\
\text { swingby } \\
\text { Mars } \\
\text { surface }\end{array}$ & 0.62 & 1.21 & 4.4 & {$[1.5,13.1]$} \\
Lunar-long & 0.66 & 1.24 & 4.8 & {$[1.6,14.2]$} \\
$\quad$ Mars & 0.65 & 0.69 & 3.3 & {$[1.1,9.3]$} \\
swingby \\
$\begin{array}{c}\text { Mars } \\
\text { surface }\end{array}$ & 0.66 & 1.21 & 5.7 & {$[1.8,17.1]$} \\
\hline
\end{tabular}

Table 4b. Calculations of effective doses, REID, and 95\% CI for lunar or Mars missions. Calculations are near solar maximum assuming 1972 SPE in deep space segment of mission with a $20-\mathrm{g} / \mathrm{cm}^{2}$ aluminum shield

\begin{tabular}{|c|c|c|c|c|}
\hline $\begin{array}{l}\text { Exploration } \\
\text { mission }\end{array}$ & $D, G y$ & $E, S V$ & REID(\%) & $95 \% \mathrm{Cl}$ \\
\hline & & \multicolumn{3}{|c|}{ Males (40 y) } \\
\hline Lunar-long & 0.04 & 0.09 & 0.36 & {$[0.12,1.2]$} \\
\hline $\begin{array}{c}\text { Mars } \\
\text { swingby }\end{array}$ & 0.22 & 0.54 & 2.0 & {$[0.60,6.8]$} \\
\hline \multirow{2}{*}{$\begin{array}{c}\text { Mars } \\
\text { surface }\end{array}$} & 0.25 & 0.60 & 2.4 & {$[0.76,7.8]$} \\
\hline & & \multicolumn{3}{|c|}{ Females (40 y) } \\
\hline Lunar-long & 0.04 & 0.09 & 0.43 & {$[0.13,1.4]$} \\
\hline $\begin{array}{c}\text { Mars } \\
\text { swingby }\end{array}$ & 0.22 & 0.54 & 2.5 & {$[0.76,8.3]$} \\
\hline $\begin{array}{c}\text { Mars } \\
\text { surface }\end{array}$ & 0.25 & 0.60 & 2.9 & {$[0.89,9.5]$} \\
\hline
\end{tabular}


Table 5a. $\chi^{2}$ test at solar minimum for $20 \mathrm{~g} / \mathrm{cm}^{2}$ shields for $40-\mathrm{yr}$ males on Mars swing-by mission. $\mathrm{P}\left(\mathrm{n}, \chi^{2}\right)$ is the probability materials can not be determined to be significantly different $(n=500)$. Values in bold for $P\left(n, \chi^{2}\right)<0.2$ indicate a significant improvement over aluminum.

\begin{tabular}{l|ccccc}
\hline Test Material & $E$, SV & $R E I D(\%)$ & $95 \% C L$ & $\chi^{2} / n$ & $P\left(n, \chi^{2}\right)$ \\
\hline & \multicolumn{5}{|c}{ All Uncertainties } \\
Aluminum & 0.87 & 3.2 & {$[1.0,10.5]$} & - & - \\
Polyethylene & 0.78 & 2.9 & {$[0.94,9.2]$} & 0.05 & $>0.99$ \\
Hydrogen & 0.43 & 1.6 & {$[0.52,5.1]$} & 0.63 & $>0.99$ \\
& \multicolumn{5}{c}{ LET-dependent Uncertainties } \\
Aluminum & 0.87 & 3.2 & {$[1.9,8.7]$} & - & - \\
Polyethylene & 0.78 & 2.9 & {$[1.8,7.5]$} & 0.08 & $>0.99$ \\
Hydrogen & 0.43 & 1.7 & {$[1.0,4.2]$} & $\mathbf{1 . 1 0}$ & $<\mathbf{0 . 1 5}$ \\
\hline
\end{tabular}

Table 5b. Same as Table 5 a near solar maximum for $5 \mathrm{~g} / \mathrm{cm}^{2}$ shields.

\begin{tabular}{l|ccccc}
\hline Test Material & $E, S v$ & $R E I D(\%)$ & $95 \% C L$ & $\chi^{2} / n$ & $P\left(n, \chi^{2}\right)$ \\
\hline & 1.21 & 4.4 & {$[1.5,13.1]$} & - & - \\
Aluminum & 1.21 & All Uncertainties & - \\
Polyethylene & 0.94 & 3.5 & {$[1.2,10.8]$} & 0.14 & $>0.99$ \\
Hydrogen & 0.52 & 2.1 & {$[0.60,6.4]$} & 0.81 & $>0.99$ \\
& \multicolumn{5}{c}{ LET-dependent Uncertainties } \\
Aluminum & 1.21 & 4.4 & {$[3.0 .11 .0]$} & - & - \\
Polyethylene & 0.94 & 3.5 & {$[2.3,8.8]$} & 0.32 & $>0.99$ \\
Hydrogen & 0.52 & 2.1 & {$[1.2,5.2]$} & $\mathbf{1 . 3 8}$ & $<0.001$ \\
\hline
\end{tabular}

Table 5c. Same as Table 5 a near solar maximum for $20 \mathrm{~g} / \mathrm{cm}^{2}$ shields.

\begin{tabular}{|c|c|c|c|c|c|}
\hline Test Material & $E, S v$ & REID(\%) & $95 \% C L$ & $\chi^{2} / n$ & $P\left(n, \chi^{2}\right)$ \\
\hline & \multicolumn{5}{|c|}{ All Uncertainties } \\
\hline Aluminum & 0.54 & 2.0 & {$[0.60,6.8]$} & - & - \\
\hline Polyethylene & 0.45 & 1.7 & {$[0.52,5.6]$} & 0.08 & $>0.99$ \\
\hline \multirow[t]{2}{*}{ Hydrogen } & 0.24 & 0.9 & {$[0.27,2.9]$} & 0.77 & $>0.99$ \\
\hline & \multicolumn{5}{|c|}{ LET-dependent Uncertainties } \\
\hline Aluminum & 0.54 & 2.0 & {$[1.2,5.6]$} & - & - \\
\hline Polyethylene & 0.45 & 1.7 & {$[1.0,4.6]$} & 0.15 & $>0.99$ \\
\hline Hydrogen & 0.24 & 0.9 & {$[0.52,2.4]$} & 1.26 & $<0.005$ \\
\hline
\end{tabular}


Table 6a. Example career effective dose limits in units of Sievert (Sv) for 1-year missions and corresponding average life-loss for an exposure induced death.

\begin{tabular}{c|cc}
\hline & \multicolumn{3}{|c}{ E, Sv for 3\% REID (Ave. Life Loss per Death, yr) } \\
\hline Age, yr & Males & Females \\
\hline 25 & $0.5(15.7)$ & $0.4(15.9)$ \\
30 & $0.6(15.4)$ & $0.5(15.7)$ \\
35 & $0.7(15.0)$ & $0.55(15.3)$ \\
40 & $0.8(14.2)$ & $0.6(14.7)$ \\
45 & $0.95(13.5)$ & $0.75(14.0)$ \\
50 & $1.15(12.5)$ & $0.9(13.2)$ \\
55 & $1.5(11.5)$ & $1.1(12.2)$
\end{tabular}

Table 6b. Example career effective dose limits in units of Sievert (Sv) for 1-year missions and corresponding average life-loss for an exposure induced death.

\begin{tabular}{c|cc}
\hline & E, Sv for 5\% REID (Ave. Life Loss per Death, yr) \\
\hline Age, yr & Males & Females \\
\hline 25 & $0.9(15.7)$ & $0.6(15.9)$ \\
30 & $1.0(15.4)$ & $0.8(15.7)$ \\
35 & $1.2(15.0)$ & $0.9(15.3)$ \\
40 & $1.3(14.2)$ & $1.0(14.7)$ \\
45 & $1.6(13.5)$ & $1.25(14.0)$ \\
50 & $1.9(12.5)$ & $1.5(13.2)$ \\
55 & $2.45(11.5)$ & $1.9(12.2)$
\end{tabular}

Table 7a. Projections for males of age-dependent maximum days in deep space with 95\% CL of remaining below a risk limit, $R_{L}(\%)$. Calculations are for GCR at solar minimum with $10 \mathrm{~g} / \mathrm{cm}^{2}$ aluminum shielding comparing previous results (Cucinotta et al., 2001b) to present results.

\begin{tabular}{l|lll}
\hline Age, $\boldsymbol{y r}$ & Previous $\boldsymbol{R}_{\mathbf{L}}=\mathbf{3 \%}$ & Present $\boldsymbol{R}_{\mathbf{L}}=\mathbf{3 \%}$ & Present $\boldsymbol{R}_{\mathbf{L}}=\mathbf{5 \%}$ \\
\hline 30 & 91 & 142 & 236 \\
35 & 104 & 166 & 277 \\
40 & 122 & 186 & 310 \\
45 & 148 & 224 & 373 \\
50 & 191 & 273 & 455 \\
55 & 268 & 340 & 568 \\
\hline
\end{tabular}

Table 7b. Projections for females of age-dependent maximum days in deep space with $95 \% \mathrm{CL}$ of remaining below a risk limit, $R_{\mathrm{L}}(\%)$. Calculations are for $G C R$ at solar minimum with $10 \mathrm{~g} / \mathrm{cm}^{2}$ aluminum shielding comparing previous results (Cucinotta et al., 2001b) to present results.

\begin{tabular}{l|lll}
\hline Age, $\boldsymbol{y r}$ & Previous $\boldsymbol{R}_{\mathbf{L}}=\mathbf{3 \%}$ & Present $\boldsymbol{R}_{\mathbf{L}}=\mathbf{3 \%}$ & Present $\boldsymbol{R}_{\mathbf{L}}=\mathbf{5 \%}$ \\
\hline 30 & 54 & 112 & 187 \\
35 & 62 & 132 & 220 \\
40 & 73 & 150 & 250 \\
45 & 89 & 182 & 304 \\
50 & 115 & 224 & 374 \\
55 & 159 & 282 & 470 \\
\hline
\end{tabular}

